\title{
A pluralistic approach to economic and business sustainability: A critical meta-synthesis of foundations, metrics, and evidence of human and local development ${ }^{1}$
}

\author{
Andrea Gatto ${ }^{2}$
}

\begin{abstract}
Wellbeing and sustainability are at the center of development studies and economics, being the kernel of theories and policies. Analyzing such complex phenomena implies taking into account both the economic and business spheres. In this regard, the human and local dimensions of development have assumed central importance in determining definitions, measurements, and policies and reveal decisive implications for economic ethics and long-term development perspectives. This work intends to draw a theoretical excursus on the nexus between the human, sustainable, and local dimensions of development and wide-ranging business theories. For this scope, the paper adopts a pluralistic approach for determining diverse conceptual insights. Entangling holistic lenses, this study explores the theoretical foundations, measurements, and experiences that have characterized the recent development theory and applied evidence in economics and business. The review detects some evidence in the global and the Italian experiences that can reveal important lessons for theorists, policymakers, and practitioners in development, sustainability, and business.
\end{abstract}

KEYWORDS: business sustainability, composite indicators, human development, local development, sustainable development, wellbeing, CSR

\footnotetext{
${ }^{1}$ The author is grateful to Chiara Esposito and Luke Putres for their valuable help and two anonymous referees for their suggestions. The author shall also acknowledge further feedbacks received by specialists and practitioners during conferences, speeches and taught courses.

${ }^{2}$ Livelihoods and Institutions Department, Natural Resources Institute, University of Greenwich, Central Avenue, Chatham Maritime, ME4 4TB, UK. New College of the Humanities at Northeastern University, 19 Bedford Square, Fitzrovia, London, WC1B 3HH, UK. Centre for Studies on Europe, Azerbaijan State University of Economics (UNEC), Azerbaijan. Email: a.gatto@greenwich.ac.uk.
} 


\section{INTRODUCTION}

\subsection{New bases for development: Ethics and sustainability for countries and organizations}

The financial and economic crises impose a reinterpretation of economic, managerial, and social sciences in an ethical key. In both the scientific and the international community, the need to consolidate synergies between disciplines and sectors emerges, with the aim of structuring integrated theories and measurements (Gatto \& Drago, 2019). Some of the implications resulting from this process arise for the public sector, where an approach based on the dimensions of sustainability gradually consolidated (Meadows et al., 1972; Agovino, Cerciello, \& Gatto, 2018)-the perspective focuses on the triangulation between the economy, the environment, and the society, assisted by governance. This approach foresees a central role for the person, to be implanted in territorial dimensions (Biggeri \& Ferrannini, 2014). Other solutions have been identified for the private sector. CSR offers major contributions to sustainability (Moon, 2007), being corporate sustainability intertwined with CSR (Montiel, 2008). The gradual rethinking of company objectives is today affirming the importance of corporate sustainability, networking, and the role of the person within business processes (Stampacchia, 2014).

Both the public and private sector sustainability are accompanied by new measurements based on the most recent scientific interpretations: on the one hand, the theories of human, sustainable, and local development and on the other hand, to the corporate sustainability theories. Theories and measurements are reporting a growing consensus even within the international community (UN, 2015). As a final juncture of this process, new paradigms of economic development are emerging-the latter having the ultimate goal of enhancing the importance of a broad set of possible futures. Such pluralistic approaches embrace the role of human being and of economic and business sustainability, focused on territorial aspects and rooted in economic ethics and in corporate responsibility (Carroll, 1991).

The limits of GDP as a unique tool for assessing the state of development of a nation have gradually reached consensus in the academic and intergovernmental ambients (Lewis, 1970; Stiglitz, Sen, \& Fitoussi, 2009). The process of overpassing GDP as a measure of national and world progress is twofold: primarely, it implies the formulation of conceptualizuations of great breadth of view, encompassing broader variables for analyzing the wellbeing, quality of life and happiness. Secondarily, it requires the construction of comprehensive metrics able to capture the sketched phenomena-appropriately sinthesized by the composite indicators (Dasgupta \& Weale, 1992; Costanza et al., 2014; Qasim, 2017).

Amongst the first notable expressions of the new economic interpretation, it shall be mentioned the capability approach, the theory conceptualized in the 1980s, mainly by Amartya K. Sen and Martha Nussbaum. The capability approach found success especially in the United Nations Development Program (UNDP), due to the contributions of economists such as Sen and Mahbub ul-Haq, as part of human development studies. Starting from 1990, the capability approach consolidated, and the UN agency started dealing with the drafting of the Human Development Report (HDR) and the Human Development Index (HDI. Nussbaum \& Sen, 1993; Anand \& Sen, 1994; UNDP, 2019). The long-run has been reputed a common base for the new develpment theories; for this, the human, sustainable, and local attributes of the new development concept is shown to be strictly interconnected with the long-term perspectives analyzed by the research sector of futures studies. Such discipline revealed to be a determinant outlook to examine the capability approach (Poli, 2011).

Over the years, management studies developed measurement tools of the business performance that were more exhaustive than classic tools. This was a response to the need to go beyond the quantification of the 
mere financial result. Over time, various business theories interpreted with increasing accuracy the role of industry within the communities, as well as the actors that make up the organization and the whole enterprise (Becattini, 2002; Stampacchia, 2014). The most significant contributions come from the total quality management (TQM), the stakeholder theory, and the strands of research on service (service management, service logic, and service-dominant logic). These lines of research have paved the way for the formulation of more precise indicators, capable of synthesizing the guidelines of corporate governance in a more reliable manner. This was due to the new measurement tools that reflected more detailed, robust and exhaustive interpretations of entrepreneurial goals, which aligned more with the policies that were taking shape in a rapidly-changing world (Gatto \& Drago, 2019).

This work consists of a critical review of development theories and practices in economics and business, and focuses on sustainability and wellbeing. Making use of a holistic and pluralistic approach, the review aims at proposing novel insights from the new outcomes reached. For this scope, the article first exploits an integrative review of selected development theories, both at the economic and business level. Therefore, it is conducted a meta-synthesis, with the scope of reinterpreting the theories meaning across precedent studies. The integrative review allows for exploring the possibility of new theories and speculations, especially in conceptual and theoretical progress and more advanced exploratory studies. The final objective is to reinterpret the results gathered from the research collection and provide a contribution to the economic and business literature within the sustainability, wellbeing, and development topics.

The article is divided as follows: Section 2 explores the methodology used for this research. Section 3 reviews the theoretical approaches of human, sustainable, and local development and wideranging business theories. Section 4 examines some of the foremost indicators that have been created to compute the human, sustainable, and local dimensions for economies and businesses worldwide and in Italy. Section 5 is devoted to the exploration of some outstanding economic and business experiences, where an emphasis is attributed to Italy. Section 6 discusses the results brought from this research, on the bases of a holistic approach to long-term development and wellbeing. Section 7 concludes and launches some prospects in terms of governance, strategies and policies.

\section{METHODOLOGY}

The current work has the scope to scrutinize existing major theories connected with sustainable development in economics and business-namely, human, sustainable, and local development and the multistakeholder and service theories. On the other hand, the research aims to bring new insights to facilitate the emersion of an allencompassing conceptual approach to define, integrate, and shape existing theories. In order to test these theories and their broader and interconnected applications, a number of metrics and case studies are selected and analyzed. For this scope, the text first examines some of the sustainability indices and initiatives that have been benchmarking the sustainability and wellbeing theory and policymaking related to development in the last decades-that are the HDI, the Commission on Measurement of Economic Performance and Social Progress (CMEPSP), and the Benessere Equo e Sostenibile (BES) as measures of the economic result; the International Organization for Standardization (ISO) 26000 and the CSR Management Network-ISTAT index as business performance indicators. Thus, selected practices of Latin American constitutions and some Italian evidence are analyzed. The choice of the latter is motivated by their fitness-of-use with the mentioned theories and the attempt to provide broader lenses to analyze them. 
The methodology adopted for reaching these scopes is the compilation of an integrative, critical review, aimed at providing a meta-synthesis of existing literature on the examined topics. The review first analyzes selected approaches to address sustainability and wellbeing questions-i.e. human, sustainable, and local development, and the stakeholders and service approaches. Thus, to corroborate the methodological premises and findings, the study explores some of the most utilized, recent metrics, built from international organizations and scholarship. Therefore, for the same scopes, a number of selected good practices are analyzed. Policy implications and prospective scenario analyses are of worth for examining future applications of the review performed.

The review has been conducted following the analysis of some of the most representative theories and applications to the topics explored and the review objective. Thus, thorough text analysis has been realized, paying attention to find communalities and divergences among the theories and their implications. To follow these targets, the review proposes a critical analysis of the theories presented, in economic, historical, policy, and institutional terms. Hence, in line with past literature, the review puts forward an integrative approach to fill the existing gaps in research and policymaking, insisting on the convergence points. The results provided by the meta-synthesis and the critical integrative review deliver novel insight to reinterpret the existing consolidated theories, leaving room for discussion and stimulating advances and future debate on the topics.

\section{THEORETICAL APPROACHES}

\subsection{Human development to increase people's capabilities}

Starting from the 1980s, the revisitation of many of the assumptions underlying the economic development began to take shape and place; however, the rediscussion of the old socioeconomic paradigms and the dynamics of long-term development have become distinctive features more recently. In the last years, it became crucial the pursuit of sustainability-based economic models, aimed at overcoming the efficiencyequity dichotomy. The latter models could hence account for an emerging role attributed to the local dimension and needs, economy growth in the framework of international market integration, and humancentered focus (Costantini \& Monni, 2008). The efficacy of the interactions resulting from this threefold vision has been confirmed by the implications resulting from the Resource Curse Hypothesis and the Environmental Kuznets Curve. The novel development models had the primary mandate of going beyond the objective of measuring mere economic growth, being based on the broader concept of long-run development. This step is of principal importance when it comes to geographical appraisals: it is paramount for the case of East Asian economies in overcoming the consolidated growth models, reaching effective economic and social results, decreeing the success of developmental state and East Asian industrial policies (Stiglitz \& Uy, 1996; Gatto, 2013).

As new macroeconomic measurement tools, sensitive to the qualitative and social variables of development, a series of indicators and guidelines emerged in recent years: in macroeconomic terms, notable examples include the HDI, the CMEPSP, and the Italian workshop represented by the BES (fair and sustainable wellbeing). On the business side, remarkable examples are the Global Reporting Initiative (GRI), the ISO 26000 (measuring sustainability standards), and the CSR Management Network-ISTAT index (beyond financial data: business and collective wellbeing). These composite indicators and methodological proposals respond to the need for greater exhaustiveness compared with the traditional measurement of economic growth-GDP. ISO standards are part of a broader cluster of binding and nonbinding tools that 
can be used from both the public and the private sector. Besides ISO standards, this group includes labels, certifications, and further qualitative standards. A renowned sector is constituted by the health, safety, and hygiene at work, for which the European Union has constituted an international benchmark in the field of regulation and policymaking. The pathway targeting the overtaking of GDP as a single indicator of economic performance is long.

The idea of development as a "way to increase the scope of human choices" was not extraneous already to scholars related to classical yardsticks of production and income such as Arthur Lewis (1970); the Nobel Memorial Prize Laureate in Economics believed that the increase in the gross domestic product was capable of expanding human choices because it was able to widen the achievable basket of goods. Since its first formulation, the capability approach was grounded on a link with the quality of life (Nussbaum \& Sen, 1993). Sen identifies the critical aspects of this vision, detaching itself from the Lewisian approximation (Sen, 1999a). In human development, freedom is distinguished in two aspects: i) the procedural aspect, relevant to the decision making processes and to the achievement of the objectives considered essential. From the procedural aspect, it derives the insufficiency of the instruments of economic growth because social choices and political decisions are considered as an end of development. On the other hand, it arises the possibility aspect, which provides information on the individual's effective faculties to obtain the precious good (Sen, 1999b). In this vein, Sen's address is to complete the inquire on the real income of people with the most common indices of human and social development-essential for identifying precious assets such as the freedom of a long and healthy life, access to education and job opportunities, and a healthy and peaceful environment in which to live and raise a family.

The consensus on these issues was translated into the implementation on networks, labs, groups, and research centers that investigated the cutting-edge rationale carried from this unified approach that was able to merge the human, local, and sustainable spheres of development in a long-term perspective, considering the centrality of intergenerational change. Some of the research products in these fields achieved in Italy are due to the implementation and the efforts of research organizations in analyzing the connection between these fields into diverse socioeconomic disciplines. Among the most pertinent and recent evidence, one can mention the ARCO lab in Prato, analyzing human development and the local dimension of sustainability principles (Biggeri, Ferrannini \& Mauro, 2011), as well as the United Nations Educational, Scientific, and Cultural Organization (UNESCO) chair in anticipatory systems at the University of Trento; in this sense, futures studies, whether applied within the capability approach framework, offer essential tools for the economic and social foresight, forecasting, and scenario analysis (Poli, 2011).

\subsection{Sustainable development}

Besides being linked to the typical themes of the capability approach, the research strands mentioned above are directly related and integrate the avant-garde advanced by multiple perspectives and long-run studies. Sustainable development depends on people apart from being tailored on environmental purposes (Griggs et al., 2013). This fact yields the interconnectedness between the two approaches. Inclusiveness is a primary characteristic when it comes to sustainable development and, more generally, holistic approaches to development (Gupta \& Vegelin, 2016; UN, 2019).

One of the first blueprints of sustainable development can be derived from the lessons of the Club of Rome and Aurelio Peccei, a forerunner of sustainable development. Despite the disputed imprecisions and fallacies in the methodology, projections, and the forecast inherent in the document, the Limits to Growth 
report, commissioned by the MIT to the Club of Rome in 1972, managed to anticipate the need for a reflection on the environmental issue and on the sustainability of economic systems. This included environmental degradation, resource futures, and climate change, fueling long-term thinking and predictive analysis (Meadows et al., 1972). In the same year of Limits to Growth, the UN conference on the Human Environment-the first major international environmental summit-took place in Stockholm. In the same period, many international actions were undertaken, the last being part of the United Nations Environment Program. Sustainable development garnered consensus and popularity as well as a consequence of resulting social unrest (Gaffney, 2014). Despite its flaws, Limits to Growth remains the main legacy of the period, drawing many global governance strategies that will turn compelling for the upcoming decades. Since 1987-when the United Nations Common World Environment and Development Report entitled Our common future was published-the foundations for sustainable development at the international stage were consolidated.

The debate that helped to stimulate the Club of Rome was translated into international forums, high-profile publications, and a new agenda dedicated to the issues; amongst the others, some of the pivotal events included the Earth Summit, the 1992 UN Conference in Rio de Janeiro, which led to the Rio Declaration and Agenda 21, and the controversial 1997 Kyoto Protocol aimed at reducing greenhouse gas emissions by signatory countries. The European Commission (2010) underlined the need to achieve "measurable" objectives by 2020. The 2012 United Nations Conference on Sustainable Development, Rio +20, delivered the document The Future we want. Finally, the latest legacy of Rio +20 and the intergovernmental path on sustainable development, the implementation of the post-2015 sustainable development goals (SDGs), drafted as "an inclusive and transparent intergovernmental process, open to all stakeholders" (UN, 2015).

A number of further conferences and resolutions on specific subjects of relevance for sustainability might be mentioned-above all the UN yearly Climate Change Conferences in the framework of the United Nations Framework Convention on Climate Change (UNFCCC), of which COP 21 is considered to be a milestone. The implementation of SDGs marked the increase in goals from 8 to 17 , in the transition from sustainable development goals to millennium development goals. The transition from millennium development goals to SDGs contributed, inter alia, to move the development agenda focus toward sustainability and to include all world countries, instead of considering simply developing countries (Sachs, 2012). The new research streams undertook by sustainable development no longer refer exclusively to the environmental sphere but reflect the multidimensionality of the international development agenda, in line with the human and local priorities and the momentum of long-run and holistic perspectives and anticipation studies outlined by the approach to capacities (Agovino et al., 2018).

Real-world applications of sustainable development can be found from the institutional and business domains. Notable examples are the Latin American constitutionalism and corporate sustainability pioneering projects. The constitucionalismo andino managed to introduce into several Latin American constitutions paramount sustainability concepts-above all, common-pool resource governance. Sustainability is made fungible by the vuelta biocentrica and the pacha mama, ecological principles that allow a novel interpretation for the role of nature, and at the core of the underlying theory is the buen vivir, the living well (Melo \& Gatto, 2014). On the other hand, industry can be decisive in designing and fostering long-term thinking and sustainable production and consumption styles, as well as corporate and community wellbeing. In this framework, awareness and engagement are determinant for value cocreation within ethical consumption (Tregua, Russo-Spena, \& Casbarra, 2015). Some forerunners can be detected in Adriano Olivetti and Olivetti's major innovations, Brunello Cucinelli, a pioneer of community enhancement, quality of life, and local development. Other trailblazers include the Città della Scienza (City 
of Science) in Naples, whereby its founder, Vittorio Silvestrini, shaped an innovative solution for the longrun development of local communities through the enhancement of research and innovation (Greco \& Fraia, 2006; Sinigaglia, Gallino, Salvadori, \& Cadeddu, 2011; Zsolnai \& Wilson, 2016). All these visionary entrepreneurs promoted novel models grounded on ethics, facilitating real innovations that tangibly improved business theories and daily practices connected with wellbeing and sustainability.

\subsection{The local systems}

In this process, the third pillar, which emerged as the declination of the theories and instruments proposed in a territorial dimension, is local development. The local imprint and the role assumed by the person, as an element of the human being complex system-both within the production systems and the local communities-have acquired growing importance into the international forums (Porter, 2000). Internationally, Italy can boast a good empirical and theoretical tradition in this regard, gained with the enhancement of local industrial and craft systems as well as typical made in Italy productions (Trigilia, 2005; Becattini, Bellandi, \& De Propris, 2014). Local production systems spread in further European and nonEuropean countries other than Italy, evidencing remarkable diversity in terms of evolution features, governance and competitive advantage models (Crouch et al., 2004).

The process of rethinking the hegemonic economic assumptions was successful in consolidating the link between the person, the territory, and the small local excellence productions; in particular, the Italian academia identified "Marshallian" production systems in the "third Italy" of the center and northeast of the Peninsula for a post-Fordist company. The case studies of the districts examined, among others, by scholars such as Becattini, Brusco, and Bagnasco (Becattini, 2002), especially in the 1980s, ended up in good international practices, defining the guidelines for local economic development. In this context, the myriads of microenterprises and local small- and medium-sized enterprises (SMEs), clustered in dense productive and commercial networks, yield forms of co-opetition. These were ambients in which the organizations could compete and cooperate at the same time, generating milieux where social capital formation could flourish and, in many cases, increased standards of wellbeing and economic development, within systems characterized by broad spectrum economic and corporate sustainability (Trigilia, 2001). Although revolving around the concept of industrial district and production systems, the pivot of local development must be found above all in internal dynamics: it consists of the local dimension, capable of expressing a great value of social capital and intangible factors for development. The evidence developed on industrial systems characterized by these highly specialized and flexible SMEs involved many foreign academics, above all Piore and Sabel (1984), nurturing a trend that preserves many contingency points with human development studies (Biggeri \& Ferrannini, 2014).

The delocalization, the crisis, and the closure of a large number of districts should not be interpreted as the failure of the local production systems model; it is true that the geographical dispersion imposed by the integration of the markets and the crisis that hit the Italian industrial system imposed a reflection on the model. The poles that invested and strategically directed towards non-offshorable values and those that managed to adapt to the new needs driven by spatial business dispersion, were able to benefit from comparative and competitive advantages gained over years of operation, showing economic and social resilience (Gatto, 2014). The local resources, the know-how anchored to the territory, the social capital, and the intangible assets that proliferate within these systems have been recognized as the added value of every single company, in an era in which the network interactions have become the bases of the success of the company and of the territorial systems (Trigilia, 2001). 
There are numerous examples of areas, regions, or countries that have based their development on the economic implications of these networks. Apart from Italy, the effectiveness of the model has been confirmed elsewhere in the world. This is the case of the East Asian development experience that was based on industrial policies and the implementation of industrial clusters and science parks, as for the case of the Hsinchu Science Park (Gatto, 2013 \& 2014). It became fundamental to increase attention and to direct policies toward the revision and support of districts and productive systems; these must be reinterpreted as places where companies, institutions, research institutes, and civil society are free to interact, cooperate, and compete at the same time, launching co-opetition business strategies and generating an osmosis between industrial, commercial, social, and cultural sectors. These environments are productive systems capable of generating ambients able to feed knowledge spillovers, external economies, and externalities, to be acquired through interactions and exchanges within the milieu (Stampacchia, 2014; Piore \& Sabel, 1984; Becattini, 2002). It is precisely the link between the increase in possibilities for a community, generated by local development policies, and the concept of local development itself that underlies the bridge with the conclusions drawn by human development and the capability approach. In this perspective, the economy also performs social and environmental functions and tasks.

\subsection{From the measurement of the financial result to the sustainable business theories}

Industry is no exception when it comes to sustainability (Moon, 2007). In the last years, the private sector has been deeply involved in new theoretical formulations and metrics, with the attempt to quantify sustainability and wellbeing. The Brundtland Report and grand development agreements have been milestones for firm's responsibility and sustainability progress. However, the sustainable development discourse has been considerably shifting from Brundtland's bequest, converging towards a "managerialist emphasis" (Barkemeyer et al., 2014: 17). These variegate advances allowed to complete the gaugement of development result of systems having a macrogeographical boundary with the measurement of development results of the enterprise. Business aggregates are determinant systems when it comes to long-run and wellbeing analyses, being the other major component of the economy.

Despite the importance of the issue and the recent progress, this line of research results to be almost uncovered to date because studies usually emphasize either the macroeconomic or the business component, leaving the mesoeconomic analyses behind. The path tackled by the economic aggregates has been flanked by management theories that have been increasingly attentive to an approach oriented to economic and corporate sustainability, yielding an array of concepts (Dobers, 2009). One must trace the first analysis of the management performance to the mainstream management theories: these strands of research supported the maximization of profit as a tool for measuring corporate performance in terms of result or current value and forecasts of flows or securities (Stampacchia, 2014).

Although the maturation from classical theories toward more complete lines of analysis has served to rely on more sophisticated measurements-such as return on investment, return on equity, and economic value added-, the various measurements approaches were closely linked to some piece of accounting, economic, or monetary element. Furthermore, these theories presented the limit of being explicitly addressed to the satisfaction of a single category of stakeholders-i.e. property (or shareholders). The intention to solely satisfy this category involved the need to maximize a single type of resources, which fell within the classical material resources; therefore, a single imperative was elected as the guiding criterion of management and governance (Sciarelli, 2007). Over the years, dissatisfaction with the calls of the main 
business theories emerged, which led to the rethinking of such consolidated assumptions and requirements and, gradually, to the implementation of a multistakeholder approach.

Although the first advances in the direction of business theories taking into account the human dimension already emerged in the late 1940s, one must wait for the first half of the 1980 s to observe management studies that place the human being at the center of their speculations and the revisitation of the measurement principles of the operating result, attributable to the stakeholder theory and the TQM (Stampacchia, 2014). The TQM offered numerous insights to management theories, in particular, since the 1980s, when it strengthen in Japan. This directive strategy was carried out already on the turn of the 1940s at Toyota's plants. It was characterized on the one hand by a production system aimed at finding quality for the entire supply chain, with the ultimate goal of satisfying the customer; on the other hand, it turned crucial the use of management innovations that would have made the processes more efficient-through the just in time, lean production and the involvement of employees and suppliers. In this system, the ethical footprint reflected on the quality of work and the role of the worker in the production chain, no longer a mere gear, but a trained, self-realized technician, engineer, or worker. The main contributions to the stakeholder theory are due to Freeman (2010) yielding the turning point of the stakeholder role according to the company objectives.

From this point on, the management priorities are reviewed according to the needs of all stakeholders and not exclusively those within the company: starting from that moment, the executive boards will take into account the needs of suppliers, customers and interest groups, and lobbies that will represent an active part in the decision making process together with shareholders, managers, and employees. In this new process, ethics becomes fundamental to direct decision makers in business management activity and contribute forging the overall corporation's management decisions and governance approach pursued (Carroll, 1991). From this step, new intangible resources are contemplated together with the material ones, whereas the goods produced by the territory play a decisive role in bringing together the different spheres and needs of the groups involved and contribute to the wellbeing and sustainability of the complex organization. CSR did not reach an univocal academic definition nor an unambigous practical business interpretation. Nevertheless, CSR is widely considered to be vital for corporation's success (Danilovic et al., 2015). Firms tend to espouse CSR motivated from resource-capability or institutional acceptability rationale (Bansal, 2004). CSR becomes necessary as a meeting point between the needs of different spheres and groups and as a source of competitive advantage (Sciarelli, 2007).

Starting from these assumptions, the main lines of managerial research turn to the interest of corporate

sustainability, rooted in the territory, within networks, in consideration of the person and their interactions, and in the environmental context and the community dimension in which they live. At the same time, the fundamental role that management must attribute to all stakeholders starts becoming important. Paramount conclusions have been carried forward in recent years by other business theories: service management, service logic, and service-dominant logic. Based on the analysis of the effects for customers arising from the use of products and services and the relative generation of value (use value), these strands of research have been able to emphasize the role of the person within the corporate governance processes. Service theories have offered substantial contributions in identifying a correlation between the networks and the human relationships that take place within the company and the company performance (Stampacchia, 2014).

These new theories, based on sustainability and on the role of the individual within the management processes, have been able to highlight, in the last 40 years, the limits of mainstream business thinking and 
traditional tools for measuring management results. These innovative theories have greatly benefited from the new focus on the principles of sustainable development, which would soon merge into criteria of crucial importance, and from further advances of corporate responsibility and sustainability, measured by new performance indices and tools and nonfinancial reporting. The shareholder is no longer the person in charge of dictating the guidelines of corporate governance, and the management objectives shift from the sole maximization of the financial result and the creation of economic value to a complex system of goals, responding to economic needs, environmental, and social objectives. The resulting targets are guided by ethical principles, able to satisfy all the company stakeholders.

A new management paradigm is launched, in line with the evidence emerging at the economic level. The ultimate entrepreneurial goals become corporate sustainability objectives, understood as a continuation of business activities over time, but also as the impact of management policies on the territory and the community. Therefore, it becomes essential to ensure the financial, economic, environmental, and social stability of the company, responding to the needs of all stakeholders, on which the continuation of activities depends, and creating not only economic value but also social and territorial value in the long term, to be allocated to the community in which the organization is located. Thus, the company manages to be a third party to the stakeholders and, pursuing the goals of sustainability through an ethical approach, generates economic and social development. Based on these new management paradigms, it emerges a theory of business sustainability based on corporate responsibility, capable of integrating with the theories of sustainable, human and local development that has its roots in economic ethics. This pathway has allowed to implement and disseminate integrated macroeconomic and business sustainability measurement tools.

\section{NEW MEASURES FOR ECONOMIC AND BUSINESS RESULTS: SUSTAINABILITY, WELLBEING, AND CSR INDICES IN THE WORLD}

Nowadays, the need for extensive formulations of new language and economic content requires the overcoming of the mere operating result and GDP measurement. This breakthrough calls for new instruments for the robust measurement of economic and business performance. The most recent CSR directives confirm the need to associate ethics to territorial and management sustainability with economic development (Biggeri \& Ferrannini, 2014). These are coupled by certification standards related to the social and environmental responsibility of companies, public administrations and organizations (above all ISOs), directives, and regulations on health and safety at work (Commission of the European Communities, 2004), as well as the new forms of reporting based on participatory democracy, on management transparency and anti-corruption-social, sustainability and ethical budgets. The private sector has now assumed the role of protagonist of this social change, driven by the need to redress the task and identity of the entrepreneurinnovator. At the same time, industry is called to bring into the management objectives a new value system whereby the purpose of corporate sustainability goes hand in hand with the broader aim of territorial sustainability. Innovation and cultural change become priority objectives of management, even before the change in management, placing the ultimate target of creating final value for the community, rather than short-term financial indices.

Methodologically, composite indicators have been detected as reliable measures to quantify and depict complex phenomena. In the last years, more robust measures have been adopted by both academia and development agencies, with the scope to produce sound indicators, applicable to compelling policy purposes (Gatto \& Drago, 2019). Composite indicators addressing development facets have been 
increasingly adopted to gauge aspects affecting the poor, women, rural people, and vulnerable categories (Nussbaum, 2001) or resource vulnerability (Gatto \& Busato, 2020). The final scope of composite indicators is to propose measures capable to facilitate resilience policies and encourage their application, facilitating their communication and usability (Gatto \& Drago 2020a, 2020b).

\subsection{HDI, CMEPSP, BES, and ASviS}

In the international forums, the need to identify indices able to summarize economic and social development in place of growth finds an answer in new measures of wellbeing, starting from the action of UNDP with the HDR and the HDI. This pillar was followed in the EU by the Stiglitz-Sen-Fitoussi Commission (Stiglitz et al., 2009), which in Italy found application in March 2013 in the BES (fair and sustainable wellbeing), following a research path that lasted over 2 years. In June 2013, the latter was eventually formulated for the cities (UrBES) and the Provinces (BES delle Province). These Italian projects are led by the ISTAT and the National Council of Economy and Labor, immediately emerging as international avantgardes (ISTAT, 2015). Along with these projects, Italy benchmarked global efforts for producing and reconciling domestic analyses, perspectives and metrics for sustainable development jumpstarting the ASviS (Allenza italiana per lo Sviluppo Sostenibile) group. Born in 2016, the ASviS is the largest Italian multistakeholder network and is the expression of greatly diverse groups and interests converging towards sustainability goals (ASviS, 2019). Some of the organizations that adhered to this network actively analyze diverse approaches to development. The ASviS is composed, inter alia, by research organizations active on economic and business research and conducting projects on sustainability, wellbeing and the quality of life. These organizations include the CED - Center for Economic Development and Social Change and the Associazione Italiana per gli Studi sulla Qualità della Vita (AIQUAV). Their scope is to explore complex phenomena, cross-cutting topics and hot bottom issues and to provide holistic approaches and foresight to face vulnerability and foster resilient governance. Amongst their streams of research, the focus on metrics and composite indicators analysis and implementation is central.

The HDR is the annual UNDP report that collects the results of individual countries in terms of human development. Within the HDR, since 1990, the performances are analyzed according to the HDI criteria (Anand \& Sen, 1994). ${ }^{3}$ Since 2010, important methodological change have been integrated into the HDI, achieved by weighing inequality adjustments between countries. ${ }^{4}$ As mentioned, the need for new measures to calculate wellbeing in a comprehensive manner led to the creation of the Stiglitz-Sen-Fitoussi Commission (CMEPSP). The three scholars in their study advanced five recommendations and eight

\footnotetext{
${ }^{3}$ (a) GDP; (b) years of average and expected literacy; and (c) life expectancy at birth.

${ }^{4}$ The new HDI underpinned major improvements: 1) the shift in the aggregation method used from an arithmetic to a geometric mean, allowing for improved sensibility of the index resulting from the variables changes; 2 ) the input of new variables for the education dimension - the total mean of schooling and the expected schooling years; 3 ) the substitution of GDP with GNI for the economic dimension, allowing for a more precise calculation of remittances and income from citizens and businesses earned abroad; 4) the adoption of the natural logarithm instead of the common logarithm to explain diminishing marginal benefit of income; and 5) the change in both the upper and lower goalposts used to normalize the index in the dimensions calculation - switched from predetermined values to benchmark, real values. Despite its notable foundational limits - its simplistic structure and methodology, its lack of robustness and the neglect of the environmental dimensions -, the conceptual and methodological refinements embedded in the updated version of the HDI shall be remarked. Along with them, the outburst of keeping the index abreast with occurring development advance and the holistic view envisaged in it, allow contemplating a plethora of possible variations on the theme from the benchmark index (Klugman, Rodríguez, \& Choi, 2011).
} 
dimensions to be used as baselines for defining wellbeing. ${ }^{5}$ In the BES formulation, different sectors became important in the elaborations of the ISTAT and National Council of Economy and Labor, defined as the "12 dimensions of wellbeing, of an economic nature, but which must also take into account the fundamental social and environmental dimensions of wellbeing, accompanied by measures of inequality and sustainability" (ISTAT, 2015). The 12 dimensions are divided into a total of 134 indicators. Albeit the same 12 domains of the BES wellbeing they are referred to, the set of indicators for the UrBES report is less complex. Nonetheless, in the 2015 report, 25 to 64, as well as the municipalities participating in the initiative, have increased from 15 to 29 . These exercises present relevant advances with respect to those used, albeit with great effort and innovativeness, at the international level-the HDI can be used as an examples. These novel metrics are qualitatively decisively more exhaustive and quantitatively much more complete and sound sets of indeces.

\subsection{GRI, ISO 26000, and the CSR management network-ISTAT index}

The theoretical pathway leading to the elaboration of business performance indices has gone through the construction of methodologically more robust instruments. Over the years, CSR measurements have gained increasing attention (Dobers, 2009). Corporate sustainability metrics have often been focusing on diverse stakeholders perspectives (Antolín-López et al, 2016). Among the evidence, one can mention the corporate social performance model and the sustainability balanced scorecard. The most important and updated initiatives in this field are the vademecum advanced by the GRI, and the ISO 26000 developed by the International Organization for Standardization, which have gained international prominence.

In 2000, the GRI launches the first guidelines for the sustainability report, addressed to any type of public or private organization, of any size. The aim was to provide itself with this tool to report the economic, social, and environmental impact of its own management performance while improving managerial transparency. In its fourth version-2013-(G4), the GRI presented 58 standard information and 91 indicators to measure the impact of an organization's sustainability (Global Reporting Initiative, 2015). The initiative gained the approval of a large number of companies, organizations, and associations and maintained its independence, preserving synergies woven from the first years of life with the United Nations Environment Program and the Organization for Economic Cooperation and Development. In particular, they emerged the linkages between the GRI, the Global Compact and the Guidelines for Multinational Enterprises, launched by the two intergovernmental organizations.

The UN Global Compact has also benchmarked the field with its Guide to Corporate Sustainability (UN Global Compact, 2014). The document recommends to the firms to observe five principles to strive for sustainability: i) principled business; ii) strengthening society; iii) leadership commitment; iv) reporting progress; and v) local action. These prescriptions will ease the firms to operate responsibly, following universal principles, taking actions for the local society, and commit through periodic reports. The nexus between CSR and efficiency and management effectiveness in the long term is also underlined by other

\footnotetext{
${ }^{5}$ The recommendations to be addressed to policymakers and experts have been identified as follows: (a) analyse income and consumption instead of production and GDP; (b) base the assessments on families; (c) combine income, wealth, and consumption; (d) prefer medium-sized distributions; and (e) include non-market services in the income analysis. On this basis, the commission has designed eight dimensions of wellbeing: (a) material living standards (not only wealth but also income and consumption); (b) health; (c) education; (d) personal activities; (e) political weight and governance; (f) ties and social relationships; (g) environment (current and future); and (h) physical and economic security on the basis of which states are urged to produce national indicators (Stiglitz, Sen, \& Fitoussi, 2009).
} 
initiatives. The management result of organizations today can also be subjected to measurements that guarantee certification or standardization. The organization that mainly performs this task is today the ISO.

Among its standards, many are those deemed necessary to establish whether a process or a product conforms or not to the principles of sustainability in a broad sense, going to touch the fundamental ones such as safety, quality, and good management of production, processes, or products. The ISO 14000 is a notable family of standards, establishing environmental and sustainability management, regulation and law requirements for firms. Among all the standards, ISO 26000: 2010 is the one that recalls the most the standards of sustainability. This is because it entails that the guiding principles for CSR are based on the application of ethical principles and management transparency in concrete management solutions, aimed at improving health and wellbeing of the community and the promotion of good practices. Unlike other standards, the ISO 26000 does not set requirements, so it cannot be conceived as a certification.

The process of forming the criteria for acquiring the ISO reflects the international consensus on the theme of CSR: the involvement of extremely heterogeneous organizations, of various extraction and scope, public or private, large and small. Both the ISO 26000 and the GRI take into account the stakeholder analysis carried out by the stakeholder theory. The importance of public accountability in terms of social responsibility toward internal and external stakeholders is one of the many elements that unite the GRI with the ISO 26000, in an attempt to propose solutions that contribute to the sustainability of long-term development.

In addition to the BES, in March 2013, the ISTAT, together with the CSR Manager Network Italy, started leading the sustainability and longterm development guidelines in a further report, "beyond the financial data: businesses and collective wellbeing". Based on the assessment of environmental, social, and private sector governance performance according to the development and sustainability precepts, the report proposes 10 indicators considered of major relevance by the ISTAT-GRI synthesis. The aim was to unifying and reorganizing the multitude of methods of calculation used by companies to evaluate their performance (CSR Manager-ISTAT, 2015). An essential step was to equip the company with a double contribution of internal and external communication: on the one hand, the need to refer to sustainability reports for a series of data would be exceeded, which could, however, be partial because they are subject to the specific guidelines of the same company; on the other hand, the choice of companies to adopt this reporting, enhancing the information value, would be fostered.

This tool would integrate sustainability reports with national macroeconomic records, providing a streamlined and intelligible document, an immediately-usable and -comparable tool, sensitive to periodical deviations and therefore to monitoring, anticipation, and strategic corporate orientation. The set of performance indicators is particularly effective in underlining a bridge between the managerial and economic sustainability, between the BES and CSR, and between institutions and businesses, able to sketch the private sector contribution to the national wellbeing, within the environmental, social, and governance logic. Also in this case, the measurement would be fundamental both for the decisions of external and internal stakeholders. Addressing the company analysis, the index developed by the CSR Management Network Italia and the ISTAT summarizes the 57 indicators proposed by the GRI (CSR Manager-ISTAT, 2015). ${ }^{6}$

\footnotetext{
${ }^{6}$ The following parameters are examined: (a) Direct economic value generated and distributed (corresponding to the EC1 indicator of the GRI); (b) direct energy consumption (EN3); (c) expenses and investments to protect the environment (EN30); (d) total direct and indirect greenhouse gas emissions (EN16); (e) composition of employees
} 
Another relevant instrument is the SDG Compass, created by the GRI, the World Business Council for Sustainable Development and the United Nations Global Compact. The document, presented in parallel to the agreements for the approval of the Agenda 2030, provides a vademecum to facilitate the application of the SDGs in a company. The SDG Compass requires the essential steps of the implementation of a strategic framework of sustainability within the company and of the company activities, followed by communication and reporting of the real and impact possible futures concerning operations and objectives achieved, in economic, environmental, and social terms (UN Global Compact, 2015). ${ }^{7}$

\section{ECONOMIC AND BUSINESS EXPERIENCES}

\subsection{Selected experiences from East Asia, Latin America, and the EU}

It is of worth analyzing the selected worldwide evidence, with the goal to emphasize the possibility of having unified holistic guidances for wellbeing and sustainable development. The following experiences can be considered for diverse reasons as good practices of economic and business result, emerging as interesting prospects to reinterpret consolidated economic assumptions. To this end, this section explores the cases of the East Asian development policies, the Latin American constitutions, the EU Health and Safety at Work benchmark, and Olivetti, Cucinelli, and the Città della Scienza of Naples as business pioneers. Being the paper suggesting a pluralistic approach to entangle the discussed topics, the options reported are only some of the potential, viable explorations, instructive cases not having the ambition of being treated as compulsory pieces of evidence.

The success of the development policies experienced by the East Asian economies occurred first in Japan, then in South Korea, Taiwan, Singapore, and Hong Kong-the Asian Tigers-, therefore in some of the ASEAN countries (Gatto, 2013). The path aroused scientific interest for the speed of economic growth achieved, together with the goodness and breadth of the social results obtained (Agovino et al., 2018). This evidence, due to the high growth rates of production, and accompanied by a good distribution of income and social development, has decreed the Asian miracle. The region has based its course on a defined system of rules and regulations, the result of a widespread millennial culture of ethical principles: in the regional societal model, it is tangible as an approach based on strategic and collaborative loyalty, which finds its maximum expression in the work ethic, a factor that has contributed significantly to the regional entrepreneurial flourishing. For this reason, it turns pivotal the contribution drawn from the classic Oriental philosophies, such as Confucianism, from which derives that apparently oxymoronic neologism, known to the academia as the Confucian capitalism, with reference to the mix between the capitalist economy and the millennial culture of the ethical grounds (Gatto, 2013).

It must be recognized that the association between the rapid economic growth and social development that has taken place in these realities and the widespread education, achieved effectively and efficiently in a short time-span. A typical characteristic of the East Asian development systems was the recourse to external economies, knowledge spillovers and economies of learning. Implemented policies that included

(LA1); (f) Staff turnover (LA2); (g) average annual training hours per employee (LA10); $(\mathrm{h})$ ratio of basic salary of men and women (LA14); (i) postmaternity return rate (LA15); and (j) number of violations for discrimination (HR4).

7 "To understand how a company impacts the SDGs, it is important to realize how business activities translate into economic, environmental, and social impact." (The guide for business action on the SDGs; GRI, WBCSD, UNGC, SDG Compass, 2015). 
the investment in education that foresaw sending of the future national leadership in highly-specialized regions and the subsequent repatriation of the educated/trained human resource. Other typical policies that were subsequently applied were the investments in industrial agglomerations and eventually business facilitation and scientific osmosis. The creation of social occasions favors the direct expansion of human capability, guaranteeing a better quality of life through the advancement of elements such as security, education, and health system.

The effects produced by human development, therefore, become much more important than the mere economic growth; in addition to the recorded production levels, The results of the quality of life rates experienced at the regional level were outstanding. With the developmental bureaucratic state, in East Asia emerged a structure based on an ethical, social, and ecological mandate, where learning and work turned crucial. The setting was reflected at the firm level in the TQM, an Asian response to the crisis of Fordism. Finally, the contribution offered by local development, which in particular in business realities such as Taiwan, where the local production districts, and in particular the science parks, have emerged as a driver for economic development (Agovino et al., 2018; Gatto, 2014).

As a product of the growing presence of Latin American law in the protection of different social groups, the basic personal rights, are experiencing a deep rediscussion: the latter consists of a radical revisitation that is taking place through the emergence of the role of commons, considered as essential goods for integration and to the complete expression of the human being in his environment. In the wake of the Canadian constitution, the last 30 years have been characterized by the drafting of constitutions by numerous states of the area, placed to protect the rights of various categories, minorities, social, ethnic, and vulnerable groups. Amongst the various Latin American constitutions that emerged, the importance of some specific text should be remarked: the Brazilian Constitution has been pioneering the regional pluralism, whereas the most recent constitutions of Ecuador and Bolivia are reputed the most notable advances amidst the constitucionalismo andino: these texts explore the needs of people, designed according to the relationship between the human being and the nature and their cultural heritage. The novo constitucionalismo has its roots in a reversal of the conception of people, the doxa is that of a new, concrete humanism, inserted in a social framework characterized by economic, cultural, and juridical pluralism (Wolkmer, 2014; Melo \&Gatto, 2014).

Amongst the numerous innovations elaborated by the constitutionalism, one must highlight some pivotal ecological concepts: the Pachamama, the Mother Earth according to which the daily action should be converged; the buen vivir, which identifies the vision of a qualitative life as the guiding thread of the political, economic, and social lines; and the sumak kawsay, that is intended as the communion between people and nature. The philosophy of buen vivir has to be embedded in the concept of biocentrismo, an approach that proposes a re-interpretation of the economic, social, environmental and governance paradigm with an emphasis on the role of the person, the environment and their relationship with the territory. The latter highlights the protection of both natural and cultural commons, in whose framework water and land become essential elements for life, and for this deserves specific protection. It is precisely ensuring the enjoyment of commons that human's action in the fullness of the environment finds expression. To this end, the implementation of sustainability ethics and the creation and enforcement of right to nature are crucial-as enshrined from the forefront Latin American constitutions (Wolkmer, 2014).

With the biocentric vault, a real revolution of values is accomplished. This is obtainable through the rotation of the faculties of human being around planetary existence-questioning the theorization of unlimited growth. In this context, international organizations become fundamental in institutional and 
economic regards, producing reports and promoting international summits that have prospered headway and fed the debate.

In recent years, Latin America benchmarked in terms of sustainable development practices. In particular, the wave of new constitutions oriented to the principles of social and environmental protection was crucial to the progress of the international agenda and summits; the United Nations Conference on the Environment and Development of Rio de Janeiro in 1992 standed out, and the United Nations Conference on Sustainable Development in 2012 was created with the aim of restoring the environmental, social, and economic guidelines, with a view to long-term development, which is fundamental for projecting these conclusions into the new United Nations Development Goals discussed.

Albeit it is not a set of voluntary actions, but laws and directives, a crucial sector connected with corporate social responsibility is safety and health in the workplace. Prevention based on compliance with the principles of corporate responsibility usually translates into a positive impact on the drop in accidents at work and occupational diseases, with immediate financial and nonfinancial returns for the company; for the latter category, there are usually multiple benefits: higher productivity, lower compensation, lawsuits and bureaucratic documentation to produce, fewer absences and therefore greater continuity of production processes, further increase in productivity, and decrease in accidents due to greater maintenance of equipment and workplaces (Commission of the European Communities, 2004).

On the other hand, the virtuous enterprise, compliant with health and safety at work rules, often has the following benefits: tax relief, improvement of insurance premiums, public grants and subsidies. In this sector, the EU has been able to anticipate many of the lines that were then undertaken internationally. The legislation on this matter is not only aimed at multinationals and large companies: even micro-, small-, and medium-sized enterprises are called to search for models of social sustainability. The protection of the parameters of health, safety, and hygiene in the workplace is among the most important and decisive set of policies in the business and economic sphere carried out by the EC. The legal basis goes back to the Framework Directive for Occupational Safety and Health (OSH), entered into force in 1989-Directive 89/391/EEC on measures to improve health and safety at work (Council of the European Union, 1989). The Occupational Safety and Health Unit is one of the EC units that achieves the greatest impact on the lives of European workers through the consolidation of increasingly detailed and effective regulation.

The regulation on occupational safety and health consists of 24 directives aimed at promoting studies and good prevention practices in every type of sector of activity, both public and private (Commission of the European Communities, 2004). The areas of intervention involve directives aimed at jobs, equipment, categories of workers, physical agents, Chemical products, carcinogens, biological and asbestos, ergonomics, occupational disturbances, and socioeconomic aspects. To disseminate European directives on health and safety at work and create safer and healthier working environments, especially in SMEs, the EC collaborates with the European Agency for Health and Safety at Work and the Foundation European for the Improvement of Living and Working Conditions. Finally, in order to implement and monitor the EU legislation on health and safety in the workplace, the Workplace Safety and Health Unit relies on three Committees made up of national experts: the Advisory Committee on Safety and Health at Work (ACSH), the Scientific Committee on Occupational Exposure Limits (SCOEL), and the Committee of Expert Labor 
Inspectors (SLIC). ${ }^{8}$ Despite the results achieved, numerous critical issues that sometimes mean into a clear delay in the application of the directives in various member states must be pointed out.

\subsection{The new business humanism: Olivetti, Cucinelli, and the Città della Scienza of Naples}

Selected business experiences can be outlined as good practices of long-run development and wellbeing. For this scope, a selection of three case studies that emerged in Italy are worthy to be examined. The first good practice can be found in a company that has marked the Italian industrial history since the early 20th century: Olivetti, a Piedmontese company, a leader in the production of typewriters and electronics. The company of Ivrea stands out in numerous fields: a pioneering firm in technological innovation, able to boast among its many records the first history transistor computer and the first commercial programmable desktop computer, progenitor of the current personal computer -the Olivetti Programma 101 (Perottina or P101). Olivetti was a forerunner of trends and fashions, able to excel at an international level in the fields of design, graphics, and industrial architecture, and a national champion for turnover and number of employees (Berta, 2016; Sciarelli \& Tani, 2015).

The paramount aspect that denoted Olivetti was its approach in terms of environmental and social responsibility, formulated with decades of advance in comparison to national and international trends and standards. These policies can be found in many governance strategies, carried out in particular during the direction of Adriano Olivetti, from 1932 to 1960 (Olivetti, 2014): from working conditions, aimed at the individual's work wellbeing, to the design of offices and workplaces capable of fully integrating with the surrounding environment and for which the headquarters of Pozzuoli was built as the banner of a new corporate humanism - decisively too innovative to be understood, accepted and supported in Italy in 1955. For these reasons, the industrial city of Ivrea was included in the world heritage list by UNESCO, being recognized as "a model social project" expressing "a modern vision of the relationship between industrial production and architecture" (UNESCO, 2018).

Olivetti's corporate policies were characterized by a strong anchoring to the territory, with the aim of generating a local economic and social impact in terms of work. These policies aimed at improving the quality of life of employees and local communities. According to Adriano Olivetti's interpretation, these objectives could only be achieved through corporate culture, the promotion of local development principles, and a clear impulse toward the future (Berta, 2016; Sinigaglia et al., 2011). Olivetti's philosophy was precursor not only for the intuition that the company management objectives should go beyond the yearly profit goal but sensing decades in advance the importance of the human side of the company, as well as primary factors such as the technological innovation and internationalization for the development of the activity and the territory on which it is located. The inaugural speech of the Olivetti branch in the Naples area, "Ai lavoratori di Pozzuoli" is nowadays designated as a forerunner companion of sustainabilityoriented corporate management. The business practices carried out by the engineer in Ivrea were so anticipatory that some of them would be included some decades later in the 2001 European Commission Green Paper (EC, 2001). The thought of Adriano Olivetti began to be fully metabolized only in recent times, advancing an important legacy both in the development of the most up-to-date business strategies and in the reworking of the bases of economic ethics and business responsibility, at the theoretical level and for the economic aggregates.

\footnotetext{
${ }^{8}$ Nevertheless, significant monitoring is now provided by the Italian Chamber system, which accurately reports the latest business and national measures.
} 
Regarding the territory and the enterprise with a human touch, one cannot fail to mention the industrial interpretation of Brunello Cucinelli. It is precisely the return to the territory the distinctive element of the business success of the cashmere entrepreneur. The workplace on a human scale in the Umbrian couturier philosophy is declined in the research regime of beauty and creation of value for the community in which it operates (Zsolnai \& Wilson, 2016). A crucial aspect of the business process is the dignity, the gratification of the workers, through working conditions, and productions characterized by high-quality standards, especially for the craftsmen: respect for the times and phases of rest, facilitation of social interactions, increase of the minimum salary, and social services. These policies have benefited the motivation, health, and production performance: if it is true that work can be hard in Solomeo, it is also true the burden is not felt, people get sick and injured less, and phenomena like absenteeism are rarely registered (Rinaldi \& Testa, 2013).

This way, the cultural project of symbiosis between the family business and the village of location was shaped. The wellbeing of the "collaborators", the "thinking souls", even goes so far as to be interpreted as a business responsibility toward humanity; this recalled the restoration of the medieval village and the castle of Solomeo by Cucinelli-which has become the company's headquarters-, for the creation and renovation of parks, libraries, theaters, and structures that facilitate social interaction and increase the quality of life (La Rocca, 2014). In this respect, the operating profit is tripartite, allocating one third to community improvement work and one third to the employees. Cucinelli's rationale recalls Robert BadenPowell's legacy, striving to leave this world a little better than it was found.

In Cucinelli's business strategy, many ethical interpretations of the great thinkers of the past can be found: from Socrate to San Benedetto, to Seneca and Kant, and, above all, the new humanism of Adriano Olivetti and his "industrial village". Also in the management of production processes, ample space is assigned to the craftsmanship of the workings of skilled Italian artisans and professionals, fundamental for creating the uniqueness and the value of the garments, as is the quality of raw materials. This management approach, defined for its traits as humanistic capitalism, based on "polite" growth and oriented toward long-term development, has resulted to be fruitful, giving impetus to continuous growth in turnover and decreeing Brunello Cucinelli as the leading brand of cashmere of the finest Italian fashion.

In Taiwan, one of the most flourishing multinational corporations in the technology sector, Acer, built the same years in which Brunello Cucinelli settled in Solomeo-between 1987 and 1990-the Acer Aspire Park. The village consists of a residential center built in geographic contiguity with the Longtan Science Park, part of the largest Hsinchu cluster, in Taiwan (Gatto, 2014 \& 2013). Taiwan is the Asian Tiger which has better assimilated the local development lesson, which implemented milieux of technological research, training of human resources, socialization, and free time. Whether in Italy or Taiwan, the investments to address local development have demonstrated to play a crucial role in cultivating the future researchers, managers, engineers, and workers, building networks and environments where these professionals can find wellbeing and a scientific culture due to the presence and interaction between universities, research centers, laboratories, think tanks, institutions, and competing and allied companies.

Another testimony of territorial development model, which has rooted its bases in principles of social and environmental sustainability and has placed people at the center of the management processes, comes as well from the Phlegrean area of Naples. It consists of a research and innovation organization -the Città della Scienza of Bagnoli. In the autumn of 1987 the "Futuro Remoto" project was presented at the Mostra d'Oltremare of Fuorigrotta; the exhibition, entitled "A journey between science and science fiction", attempted to be the first major event of scientific popularization in Italy. The event was rooted in the 
thought of the founder, the physicist Vittorio Silvestrini: a Southern model of development, able to respond to the Northern industrial model (Greco \& Fraia, 2006). Similarly to Olivetti, also Silvestrini is a North Italian intellectual who has been able to identify great prospects for development in the peculiarities of Southern Italy.

The City of Science represents a new economic paradigm based on culture, scientific dissemination, and on the enhancement of the territory. It is a pole which experimented a model of knowledge economy, a knowledge industry based on the quaternary sector, research centers, museums, spaces for dissemination, conferences and debates, business incubation, start-up and business facilities, financial facilities, areas for associations and think tanks, and laboratories and offices and a point of attraction capable of transferring knowledge, and know-how to the entire local production force, made up of microenterprises, SMEs, crafts, and labor (Gatto, 2014). The pole constitutes a truly integrated center of science and development, grafted in symbiosis with the neighborhood and the beauty of the surrounding area, between the sea, green areas, the hills and the Bay of Naples.

Even today, the City of Science remains the only real bulwark to the desertification of the deindustrialization of the former area of Bagnoli (Raffa, 2011). At its origins, the project set the arduous aim of becoming the cultural and scientific center for the economic rebirth of Naples and Southern Italy in light of a fungible sustainable development asset. This would be fundamental for generating workforce not only for Bagnoli, but for the entire area, giving life to innovative science and technology of the country (Gatto, 2014). Nowadays, one might talk about a long-sighted project, considering that similar centers today proliferate; the expression of the Trentino physicist is today visionary, especially if one considers the effects on youth employment, "brain drain", and reconversion of former industrial areas (Subacchi, 2016; Gatto, 2014).

The entire project of the Science Center was born in accordance with the principles of local development and revitalization of the territory: the design of the structures was entrusted to Studio Pica Ciamarra, which operated the recovery of the 19th-century industrial warehouses, completing a work of industrial archaeology; in this way, the premises were integrated in full harmony with the surrounding area. Gradually, IDIS Foundation's master plan to rebuild the museum spaces facing the sea following the arson that burned most of the structures in 2013 was approved. The new project, thanks to a considerate use of materials and a respectful conception of spaces, the territory and the person, will integrate even better with the neighborhood and the environment, leaving space and views to Coroglio beach and to natural, commercial, and residential areas. The momentum for rebirth will have to draw from this nefarious episode experienced by the City of Science.

Amongst the positive signs, a significant contribution comes from the Business Innovation Centerformerly known as the Technological Center-which continues to grow and propose routes and facilities for start-ups and companies, from the preincubation phase to the consolidation and networking of the companies formed. In November 2014, the Knowledge Industry Area, a post-incubation area for innovative companies commissioned by the Città della Scienza and the Consorzio Area Tech Coroglio was launched (Contursi, 2014). The City of Science evidence emphasized the necessity for a rereading of CSR and economic ethics, to be extended to similar organizations, so that experiences like the Southern model developed by the Neapolitan pole would become the first step to reconstruct the future 30 years later, toward a new development paradigm (Gatto, 2014). And so that the project will not become the swan song of Southern Italy economy. 


\section{DISCUSSION}

\subsection{Toward new economic paradigms: The longrun perspective}

The findings of this research suggest identifying novel economic horizons for the new generations. For this scope, it becomes urgent today to turn toward the definition of new expressions of development, in lights of diverse possible futures. Internationally, experiences such as the East Asian development path offer insights and strategies for new models in which new impetus is given to investments in education, research and development, training, innovation, and technology. In this model, a key role will be played by networks, industrial district, and science parks as their hub and technology in the context of an approach to strategic international trade. Thinking, instead, about the Latin American evidence, even at the community level, it seems that the experience of a juridical system is being assimilated-a juridical system that is both the guarantor of societal and environmental priorities but also capable of redefining the latter.

For this purpose, it becomes necessary to foresee models in which the State assumes a crucial role in combining public, private, and citizen needs, supporting a proactive market. An important step is to reformulate the planning of strategic industrial policies and to understand and then transform the threats coming from the integration of the markets into opportunities for economic recovery. The final aim will be to restore competitiveness, employment and wellbeing domestically and globally, without neglecting the territorial aspects and social and cultural needs, in an approach that is able to assimilate the emerging glocal lesson.

To this end, it is pulsant the role of futures studies: the long run revealed to be a common base for all the analyzed theories. In this framework, exploring diverse landscapes can play a decisive role in forging the future we want. In designing desirable scenarios, sectors as health and safety in the workplace give hope for the EU as a benchmarking region of perspective for economic, social, and labor policy.

\subsection{Connecting the dots: A holistic approach to long-term development and wellbeing}

Precedent scholars have explored the nexuses existing among the three approaches to development analyzed in this work. This study has made reference to a stream of literature that interpreted the three conceptual frameworks explored for economic systems-human, sustainable, and local development-as intertwined elements of a more complex spectrum to examine development (Biggeri \& Ferrannini, 2014; Biggeri \& Libanora, 2011). The challenge of linking human, local, and sustainable development means to localize sustainable human development towards a novel, fungible territorial and people-centered perspective. To this end, it turns pivotal the role of the environment and the governance of natural resources for granting intergenerational wellbeing (Dasgupta, 2001). This stance demands resilience thinking aiming at tackling vulnerability. These requirements elicit foresight and prospect views from learning systems, yielding adaptation and mitigation capacity in the face of change. A strategic real-world application of these prescriptions can be found in polycentric governance models (Ostrom, 2010). The latter recommend undertaking scattered governance to better govern common-pool resources. Polycentric governance yields important resilience strategies for solving vulnerability conundrums within complex systems.

On the other hand, this research found relevant lessons from the business theories as well. A number of theories have been implemented in the last decades, especially regarding the results measurement. The most recent theories, connected with stakeholders theories and service theories, delimitate a shift in the 
discipline purposes (Antolín-López et al., 2016). In these dynamics, business sustainability and CSR have become determinant drivers of overall sustainability and wellbeing (Moon, 2007; Montiel, 2008). The change carried by current business streams of research is aligned with recent economic theories trends: the theories aim at producing novel metrics and broader ranges of analyses. The mainstreaming of long-term goals, the intergenerational view, and the satisfaction of the socioeconomic needs of a wide set of stakeholders is nowadays considered a priority. These features are today framed within holistic, pluralistic approaches to the discipline. A number of metrics and practices have been used in this work to corroborate the theories and conceptualizations reviewed. Case studies can be a worthy instrument to replicate or formulate novel strategies in light of the pluralistic approach put forward in this paper.

\section{CONCLUSION: STRATEGIES, POLICIES, AND INSTRUMENTS FOR THE NEW ECONOMIC ORDER－LOOKING FOR FUTURE(S)?}

A new economic order passes through a renewed centrality of the person, in a process of overturning the hierarchy between the nominal and the real economy (Biggeri et al., 2011). In this process, human, sustainable, and local development approaches have paved the way to a multidimensional interpretation and pluralistic approaches to wellbeing, quality of life and happiness measurement (Becattini et al., 2014; ul-Haq, 1995; Meadows et al., 1972). The business sector also benefits from these changes, finding improved and wider solutions for a broader set of stakeholders and scopes looking at long-run corporate objectives and measures (Danilovic et al., 2015). Nowadays, it is compelling to find novel solutions for fostering access to finance. This would be feasible making use of tools that have become fundamental for the resumption of productive activities, services, and quaternary sector, and above all, microfinance instruments such as programs dedicated to small savings and insurance, remittances, and microcredit, development tools that have deep historical roots (Agovino et al., 2018; Gatto, 2018). These needs are answered internationally in the new measurements of wellbeing, promptly bloomed in Italy as a reflection of the international avant-gardes. The overcoming of GDP and the integration of the latter with new qualitative economic and non-economic measurements reply to the need for new, exhaustive formulations of the economic language (Stiglitz et al., 2009).

Along these lines, the need to link ethics to economic development is confirmed by new CSR guidelines, which connect business to economic sustainability, valorizing the role of the individual in the processes and networks that characterize companies interconnections (CSR Manager-ISTAT, 2015). The new measurements of the firm's performance are of great importance and can be integrated with the latest theoretical findings gained in the academic context. Other outlooks include the use of ISO tools and other types of corporate and public administration certification of social and environmental responsibility, as well as with new forms of democratization and transparency of reporting-notable examples include participatory budgeting. Another source is CSR, with sustainability/social report and ethical budgeting. Futures studies offer a set of tools for policy analysis, both at state and private level, as for scenario analysis, foresight and forecast.

In this big picture, the private sector becomes an active protagonist of this change. The private sector is now driven by the need to redefine not only the role and the identity of the entrepreneur-innovator but also to bring corporate objectives in a cultural change perspective-even before managerial change-, linking them to the larger goal of creating value for the community rather than just profit (UN Global Compact, WBCSD: Developed by GRI, 2015) with "UN Global Compact, 2015". A critical rereading of the good practices that emerged in Italy from the private sector includes studying the bequest coming from 
entrepreneurs such as Adriano Olivetti and Brunello Cucinelli (Sciarelli \& Tani, 2015) or reality such as the Città della Scienza of Bagnoli and its "Southern model" (Greco \& Fraia, 2006). These models seem to pitch necessary steps for a sustainable rebirth of the entrepreneurial and scientific ambient in depressed countries. These practices, along with a "bottom-up" representation methodology, where the nongovernmental organizations took a strong role, are today identified as crucial pathways for the implementation of positive change agents, necessary to stimulate the structural renewal undertaken globally and compelling development policy, governance models, and the economic recovery.

This study aimed at contributing to existing literature reviewing past publications, critically analyzing connections, and launching future research and prospective policy. The paper scrutinized different development approaches, suggesting an all-encompassing economic and business conceptualization. Important lessons emerge from the review results. This work suggested a pluralistic approach to development that can be addressed to a plethora of diverse policy solutions and strategies. Potential limitations of the study can be detected in the existence of further development approaches - that in this study have not been considered-or the adoption of specific case studies in lieu of others. Future research might include the examination of further consolidated/emerging development approaches, for example, circular economy, sharing economy, blue economy, and doughnut economy. Another stream of further research might consider different review techniques, such as systematic or scoping reviews or bibliometrics. Other upcoming research might want to explore different methodologies, including the application of scenario analysis, multistakeholder approach analyses or modeling of local, human, and sustainable development, and stakeholders and service theories. 


\section{References}

Agovino, M., Cerciello, M., \& Gatto, A. (2018). Policy efficiency in the field of food sustainability. The adjusted food agriculture and nutrition index. Journal of Environmental Management, 218, 220-233.

Anand, S., \& Sen, A. (1994). Human development index: Methodology and measurement. Human Development Occasional Papers (1992-2007), HDOCPA-1994-02, Human Development Report Office (HDRO), United Nations Development Programme (UNDP).

Antolín-López, R., Delgado-Ceballos, J., \& Montiel, I. (2016). Deconstructing corporate sustainability: A comparison of different stakeholder metrics. Journal of Cleaner Production, 136, 5-17.

ASviS (2019). L'Italia e gli Obiettivi di Sviluppo Sostenibile. Rapporto ASviS 2019.

Bansal, P. (2004). Evolving sustainably: A longitudinal study of corporate sustainable development. Strategic Management Journal, 26(3), 197-218.

Barkemeyer, R., Holt, D., Preuss, L., \& Tsang, S. (2014). What happened to the development' in sustainable development? Business guidelines two decades after Brundtland. Sustainable Development, 22(1), 15-32.

Becattini, G. (2002). From Marshall's to the Italian "Industrial districts". A brief critical reconstruction. In Complexity and industrial clusters (pp. 83-106). Heidelberg: Physica-Verlag.

Becattini, G., Bellandi, M., \& De Propris, L. (Eds.). (2014). A handbook of industrial districts. Edward Elgar Publishing Berta, G. (2016). Adriano Olivetti secondo Luciano Gallino: L'impresa responsabile e il suo artefice. Studi organizzativi. n. 2, 2016, Franco Angeli.

Biggeri, M., \& Ferrannini, A. (2014). Sustainable human development (SHD) at the local level. In Sustainable human development: A new territorial and people-centred perspective (pp. 10-38). London: Palgrave Macmillan, UK.

Biggeri, M., Ferrannini, A., \& Mauro, V. (Eds.). (2011). L'analisi dello sviluppo umano e sostenibile a livello locale. Dossier UmanamENTE.

Biggeri, M., \& Libanora, R. (2011). From valuing to evaluating: Tools and procedures to operationalize the capability approach. In Children and the capability approach (pp. 79-106). London: Palgrave Macmillan.

Carroll, A. B. (1991). The pyramid of corporate social responsibility: Toward the moral management of organizational stakeholders. Business Horizons, 34(4), 39-48.

Commission of the European Communities (2004). Communication from the Commission to the European Parliament, the Council, The European Economic and Social Committee and the Committee of Regions on the practical implementation of the provisions of the Health and Safety at Work. Directives 89/391 (Framework), 89/654 (Workplaces), 89/655 (Work Equipment), 89/656 (Personal Protective Equipment), 90/269 (Manual Handling of Loads) and 90/270 (Display Screen Equipment). Brussels, 05.02.2004. $\operatorname{COM}(2004) 62$ final.

Contursi, M. (2014). Un Polo Tecnologico per il Sud: il caso del BIC di Città della Scienza. Retrieved at http://www.ced-center.it/2014/05/01/unpolo-tecnologico-per-il-sud-il-caso-del-bic-di-citta-della-scienza/ 
Costanza, R., Kubiszewski, I., Giovannini, E., Lovins, H., McGlade, J., Pickett, K. E., ... Wilkinson, R. (2014). Development: Time to leave GDP behind. Nature News, 505(7483), 283.

Costantini, V., \& Monni, S. (2008). Environment, human development and economic growth. Ecological Economics, 64(4), 867-880.

Council of the European Union (1989). Council Directive 89/391/EEC of 12 June 1989 on the introduction of measures to encourage improvements in the safety and health of workers at work.

Crouch, C., Le Galès, P., Trigilia, C., \& Voelzkow, H. (2004). I sistemi di produzione locale in Europa, il Mulino.

CSR Manager-ISTAT (2015). Oltre il dato finanziario: Imprese e benessere collettivo. L'importanza dell'armonizzazione tra bilanci sociali delle grandi imprese e statistiche ufficiali.

Danilovic, M., Hensbergen, M., Hoveskog, M., \& Zadayannaya, L. (2015). Exploring diffusion and dynamics of corporate social responsibility. Corporate Social Responsibility and Environmental Management, 22(3), 129-141.

Dasgupta, P. (2001). Human well-being and the natural environment. Oxford University Press.

Dasgupta, P., \& Weale, M. (1992). On measuring the quality of life. World development, 20(1), 119-131.

Dobers, P. (2009). Corporate social responsibility: Management and methods. Corporate Social Responsibility and Environmental Management, 16(4), 185-191.

European Commission (EC) (2010). Communication from the Commission Europe 2020: A strategy for smart, sustainable and inclusive growth. Brussels, 3.3.2010COM(2010)2020.

European Commission. Directorate-General for Employment. (2001). Promoting a European framework for corporate social responsibility: Green paper. Brussels: Office for Official Publications of the European Communities.

Freeman, R. E. (2010). Strategic management: A stakeholder approach. New York: Cambridge University Press.

Gaffney, O. (2014). Quiet green revolution starts to make some noise. Nature News, 505(7485), 587.

Gatto, A. (2013). II modello di sviluppo asiatico: Spunti per un capitalismo etico tra crescita benessere, in Futuri, anno 1 n. 1, IIF Press, Napoli.

Gatto, A. (2014). II parco scientifico di Hsinchu e il distretto tecnologico di Bagnoli, in Futuri anno 1, n. 4, IIF Press, Napoli.

Gatto, A. (2018). Historical roots of microcredit and usury: The role of Monti di Pietà in Italy and in the kingdom of Naples in XV-XX centuries. Journal of International Development, 30(5), 911-914.

Gatto, A., \& Busato, F. (2020). Energy vulnerability around the world: The global energy vulnerability index (GEVI). Journal of Cleaner Production, 253, p.118691. https://doi.org/10.1016/i.jclepro.2019. 118691

Gatto, A., \& Drago, C. (2019). A compound index of renewables consumption. London: NCH Working Papers Series. 
Gatto, A., \& Drago, C. (2020a). A taxonomy of energy resilience. Energy Policy, 111007, 136.

Gatto, A., \& Drago, C. (2020b). Measuring and modeling energy resilience. Ecological Economics, 2020. https://doi.org/10.1016/i.ecolecon.2019. 106527

Global Reporting Initiative (2015). G4 Sustainability Reporting Guidelines.

Greco, P., \& Fraia, A. (2006). La Città della scienza: storia di un sogno a Bagnoli (Vol. 158). Italy: Bollati Boringhieri.

Griggs, D., Stafford-Smith, M., Gaffney, O., Rockström, J., Öhman, M. C., Shyamsundar, P., ... Noble, I. (2013). Policy: Sustainable development goals for people and planet. Nature, 495(7441), 305-307.

Gupta, J., \& Vegelin, C. (2016). Sustainable development goals and inclusive development. International Environmental Agreements: Politics, Law and Economics, 16(3), 433-448.

Istat. (2015). Bes 2015: Il benessere equo e sostenibile in Italia. Italy: Istituto Nazionale di Statistica.

Klugman, J., Rodríguez, F., \& Choi, H. J. (2011). The HDI 2010: new controversies, old critiques. The Journal of Economic Inequality, 9(2), 249-288.

La Rocca, D. (2014). Brunello Cucinelli: A humanistic approach to luxury, philanthropy, and stewardship. Journal of Religion and Business Ethics, 3 (1), 9.

Lewis, W. A. (1970). The development process.

Meadows, D. H., Meadows, D. L., Randers, J., \& Behrens, W. W. (1972). The limits to growth; a report to the club of Rome. New York, 102, 27.

Melo, M. P., \& Gatto, A. (2014). Agua como bem comum no quadro da governança democrática: algumas reflexões críticas a partir das bases da economia ecológica e sobre a necessidade de um novo direito público. Novos Estudos Jurídicos, 19(1), 95-121.

Montiel, I. (2008). Corporate social responsibility and corporate sustainability: Separate pasts, common futures. Organization \& Environment, 21(3), 245-269.

Moon, J. (2007). The contribution of corporate social responsibility to sustainable development. Sustainable Development, 15(5), 296-306.

Nussbaum, M., \& Sen, A. (Eds.). (1993). The quality of life. Oxford University Press.

Olivetti, A. (1959). "Ai lavoratori di Pozzuoli" Discorso di Adriano Olivetti per l'inaugurazione dello stabilimento di Pozzuoli, 23 aprile 1955. Tratto da: A. Olivetti, "Città dell'uomo". Milano: Edizioni di Comunità.

Nussbaum, M. C. (2001). Women and human development: The capabilities approach (Vol. 3). New York: Cambridge University Press.

Olivetti, A. (2014). L'ordine politico delle comunità. Edizioni di comunità.

Ostrom, E. (2001). Vulnerability and polycentric governance systems. IHDP Update, 3(01), 1-4. 
Ostrom, E. (2010). Beyond markets and states: Polycentric governance of complex economic systems. American Economic Review, 100(3), 641-672.

Piore, M. J., \& Sabel, C. F. (1984). The second industrial divide: Possibilities for prosperity (Vol. 4). New York: Basic books.

Poli, R. (2011). Ethics and futures studies. International Journal of Management Concepts and Philosophy, 5(4), 403-410.

Porter, M. E. (2000). Location, competition, and economic development: Local clusters in a global economy. Economic Development Quarterly, 14(1), 15-34.

Qasim, M. (2017). Sustainability and wellbeing: a scientometric and bibliometric review of the literature. Journal of Economic Surveys, 31(4), 1035-1061.

Raffa, M. (2011). Napoli Innovazione e Sviluppo. Napoli: Edizioni Scientifiche Italiane.

Rinaldi, F. R., \& Testa, S. (2013). L'impresa moda responsabile: integrare etica ed estetica nella filiera. EGEA spa.

Sachs, J. D. (2012). From millennium development goals to sustainable development goals. The Lancet, 379(9832), 2206-2211.

Sciarelli, M., \& Tani, M. (2015). Sustainability and stakeholder approach in Olivetti from 1943 to 1960: a lesson from the past. Sinergie, 96 (Jan-Apr).

Sciarelli, S. (2007). Etica e responsabilità sociale nell'impresa. Giuffrè Editore.

Sen, A. (1999a). On ethics and economics. OUP Catalogue.

Sen, A. (1999b). Development as freedom. Oxford: Oxford University Press.

Sinigaglia, A., Gallino, L., Salvadori, M. L., \& Cadeddu, D. (2011). Adriano Olivetti, ovvero dell'etica della responsabilità: Conversazione tra Alberto Sinigaglia, Luciano Gallino, Massimo L. Salvadori e Davide Cadeddu.

Stampacchia, P. (2014). Le imprese nelle reti del valore: Nuove basi metodologiche per la gestione. Napoli: Liguori Editore.

Stiglitz, J., Sen, A. K., \& Fitoussi, J. P. (2009). The measurement of economic performance and social progress revisited: Reflections and overview.

Stiglitz, J. E., \& Uy, M. (1996). Financial markets, public policy, and the east Asian miracle. The World Bank Research Observer, 11(2), 249-276.

Subacchi, P. (2016). How can Italy reverse its brain drain? World Economic Forum, April, 1 2016. Retrieved on April, 26 2020. https://www.weforum.org/agenda/2016/04/how-can-italy-reverse-its-brain-drain

Tregua, M., Russo-Spena, T., \& Casbarra, C. (2015). Being social for social: A co-creation perspective. Journal of Service Theory and Practice, 25(2), 198.

Trigilia, C. (2001). Social capital and local development. European Journal of Social Theory, 4(4), 427-442. 
Trigilia, C. (2005). Sviluppo locale: un progetto per I'Italia. Roma: GLF editori Laterza.

ul-Haq, M. (1995). Reflections on human development. New York: Oxford University Press.

UN Global Compact (2015). SDG Compass. The guide for business action on the SDGs.

UN (2019). The Sustainable Development Goals Report, New York, 2019.

UN, General Assembly (2015). Transforming our world: The 2030 agenda for sustainable development, Draft resolution.

UN, Global Compact (2014). Guide to corporate sustainability, Shaping a sustainable future.

UNDP (2019). Human development report 2019: Beyond income, beyond averages, beyond today: Inequalitires in human development in the 21st century, New York.

UNESCO (2018). Convention concerning the protection of the world cultural and natural heritage. World Heritage Committee. Forty-second session, Manama, Bahrain, 24 June - 4 July 2018.

Wolkmer, A. C. (2014). Ética da sustentabilidade e direitos da natureza no constitucionalismo latinoamericano. Perspectivas e desafios para a proteçao da biodiversidade no Brasil e na Costa Rica.

Zsolnai L, Wilson D. (2016) Art-based business. Journal of cleaner production. Nov 1;135:1534-8. 